\title{
Efficacy of surgical versus conservative treatment in esophageal perforation. A systematic review of case series studies ${ }^{1}$
}

\author{
Claudia Nishida Hasimoto ${ }^{\mathrm{I}}$, Daniele Cristina Cataneo", Regina Eldib ${ }^{\mathrm{III}}$, Rafael Thomazi ${ }^{\mathrm{IV}}$, Rodrigo Severo de Camargo Pereira ${ }^{\mathrm{V}}$, \\ José Guilherme Minossi" ${ }^{\mathrm{II}}$, Antonio José Maria Cataneo ${ }^{\mathrm{VII}}$ \\ IFellow Master degree, Postgraduate Program in General Basis of Surgery, Botucatu School of Medicine, UNESP, Brazil. Acquisition and interpretation \\ of data, manuscript preparation. \\ IIPhD, Associate Professor, Division of Thoracic Surgery, Botucatu School of Medicine, UNESP, Brazil. Conception, design, intellectual and scientific \\ content of the study. \\ IIIPhD, Scientific Advisor, Evidence-Based Medicine, Botucatu School of Medicine, UNESP, Brazil. Design of the study, statistical analysis. \\ ${ }^{\mathrm{IV}}$ Graduate student, Botucatu School of Medicine, UNESP, Brazil. Acquisition of data. \\ ${ }^{v} \mathrm{PhD}$, Surgeon, Division of Gastroenterological Surgery, Botucatu School of Medicine, UNESP, Brazil. Acquisition of data.

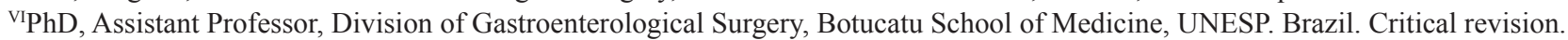

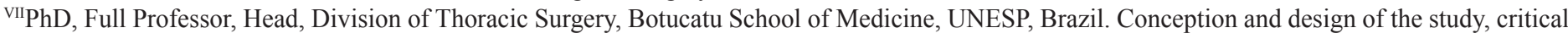 \\ revision.
}

\section{ABSTRACT}

PURPOSE: To evaluate the efficacy of surgical treatment for esophageal perforation.

METHODS: A systematic review of the literature was performed. We conducted a search strategy in the main electronic databases such as PubMed, Embase and Lilacs to identify all case series.

RESULTS: Thirty three case series met the inclusion criteria with a total of 1417 participants. The predominant etiology was iatrogenic $(54.2 \%)$ followed by spontaneous cause $(20.4 \%)$ and in $66.1 \%$ the localization was thoracic. In $65.4 \%$ and $33.4 \%$ surgical and conservative therapy, respectively, was considered the first choice. There was a statistically significance different with regards mortality rate favoring the surgical group $(16.3 \%)$ versus conservative treatment $(21.2 \%)(\mathrm{p}<0.05)$.

CONCLUSION: Surgical treatment was more effective and safe than conservative treatment concerning mortality rates, although the possibility of bias due to clinical and methodological heterogeneity among the included studies and the level of evidence that cannot be ruled out.

Key words: Esophageal Perforation. Therapeutics. Treatment Outcome. Mortality. Surgery. Drainage. 


\section{Introduction}

Esophageal perforation is a rare, difficult and challenging clinical event and there are many causes such as endoscopic examinations, surgical procedures, placement of tubes and intubation (i.e., iatrogenic causes) and non-iatrogenic causes that may include penetrating wounds (i.e., melee or fire weapons), thoracic trauma, swallowing foreign bodies or acid or caustic substances, and spontaneous rupture (i.e., Boerhaave syndrome). The most frequent cause of perforation is the iatrogenic type by upper gastrointestinal endoscopy ${ }^{1}$.

Perforations can occur in the cervical, thoracic, or abdominal esophagus. Abdominal perforations should be surgically repaired, while cervical and thoracic perforations can be managed either by repair or conservative treatment. Cervical perforations are usually more benign, but intrathoracic wounds present higher morbidity and mortality, especially when the diagnosis is made late ( $>24$ hours).

Mortality ranges between 10 and $40 \%{ }^{2-4}$, but before the antibiotic era, the rates ranged around $90 \% 0^{5,6}$.

The initial signs and symptoms are often nonspecific and lead the emergency health care professional to, initially, make other diagnose, such as spontaneous pneumothorax, acute myocardial infarction, perforated peptic ulcer, acute pancreatitis, dissecting aortic aneurysm, and pneumonia ${ }^{7,8}$.

The fact that literature lists many procedures suggests that there is no single surgical procedure considered to be gold standard for treating perforations ${ }^{7}$. Some authors support an aggressive surgical approach with primary repair or even esophagectomy with an immediate or delayed reconstruction of the removed segment and extensive mediastinal drainage ${ }^{9-11}$, while others defend an aggressive clinical treatment with thoracic drainage, broad-spectrum antibiotics, and total parenteral nutrition. For this reason we proposed determining the efficacy and safety of surgical treatment in esophageal perforation when compared to conservative treatment, through a systematic review of case series from the literature.

\section{Methods}

The present study was approved by the Research Ethics Committee from Botucatu School of Medicine - Sao Paulo State University - UNESP (REC 215/2008).

\section{Types of participants}

Studies were included if the patients of interesting presented esophageal perforation regardless etiology, age, gender or ethnicity, diagnosed by physical examinations, clinical history and/or complementary exams such as tomography and chest x-ray.

\section{Types of studies and intervention}

This review included only case series studies as there are no controlled clinical trials evaluating the role of surgery repair versus conservative treatment for the studied condition. Often to assess surgical treatment, controlled studies are difficult to perform due to many reasons. However, physicians should be acknowledged about the available existing data ${ }^{12}$. For this reason, a comprehensive systematic review of case series studies was performed.

The surgery repair was defined in this study as modalities that had directly accessed to the perforation such as the suture with or without drainage of the mediastinum and/or pleura and esophagectomy.

The conservative treatment included modalities that did not repair the fistula, but used an invasive procedure (e.g., simple chest drainage, cervicotomy or thoracotomy for drainage and esophagostomy). We also considered fasting, prolonged parenteral nutrition, use of broad spectrum antibiotics and percutaneous drainage under CT or ultrasound guidance as conservative therapies.

Articles were selected if they reported at least 20 perforation cases with more than one type of etiology, and if they assessed both surgical repair and conservative treatment.

Studies involving patients with esophagus neoplasms were excluded.

\section{Types of outcome measures}

The primary outcome of this review was mortality.

\section{Search strategy for identification of studies}

A search strategy was composed by a list of terms for 'esophageal perforation', and 'surgery repair' or 'conservative treatment' and it was run in the main electronic databases: PubMed (1966 to $11^{\text {th }}$ April, 2011), Embase (1980 to $11^{\text {th }}$ April, 2011), Lilacs (1982 to $11^{\text {th }}$ April, 2011) (Appendix). The date of the last search was $11^{\text {th }}$ April, 2011. There was no language restriction. 
Two reviewers independently selected and extracted data from the studies.

The statistical significance of the analyzed variables was tested using the Tukey's range test and chi-square test. A $p$ value was considered as $<0.05$.

\section{Results}

A total of 3311 references were identified through the main electronic databases, from which 62 potential articles were selected to further screening. From this total, 33 studies met all the inclusion criteria listed above.

Throughout the 33 included studies, 1452 patients were evaluated with a mean age of 55.2 years and $63.4 \%$ were male. Regarding the etiology of the perforations, in 788 patients it was iatrogenic (54.3\%), 294 spontaneous (20.4\%), 175 traumatic (12.1\%), 148 foreign body (10.2\%), 28 caustic (1.9\%), and in 19 $(1.3 \%)$ it was undetermined.

Twenty six articles with a total of 1147 patients referred to local perforations cervical $(n=267,23.3 \%)$, thoracic $(\mathrm{n}=758,66.1 \%)$, abdominal $(\mathrm{n}=117,10.2 \%)$; and there was no identification in five patients $(0.4 \%)$. Furthermore, six articles with a total of 256 patients classified the location as proximal $(n=49,19.1 \%)$, medial $(n=93,36.3 \%)$, and distal $(n=111,43.4 \%)$ thirds and; in three patients $(1.2 \%)$ it was not possible to identify the location. Only one article did not mention the location of the perforations.

The occurrence of signs and symptoms, the number of articles and total number of patients when reported are listed in Table 1. Not all the articles reported the clinical findings, but in those that described it pain was the most prevalent symptom (70\%) followed by fever (44\%) and dyspnea (26\%).

TABLE 1 - Demographic data of the occurrence of signs and symptoms, number of articles and number of patients.

\begin{tabular}{ccccc}
\hline Sign or symptom & $\begin{array}{c}\text { Number } \\
\text { of } \\
\text { articles }\end{array}$ & $\begin{array}{c}\text { Total } \\
\text { number of } \\
\text { patients }\end{array}$ & $\begin{array}{c}\text { Number } \\
\text { of patients } \\
\text { affected }\end{array}$ & affected \\
\hline Pain & 19 & 887 & 619 & 70 \\
Dyspnea & 17 & 815 & 215 & 26 \\
Fever & 16 & 807 & 355 & 44 \\
Emphysema & 19 & 887 & 225 & 25 \\
Pneumomediastinum & 15 & 585 & 113 & 19 \\
Nausea or vomiting & 13 & 516 & 98 & 19 \\
Pneumothorax & 13 & 527 & 175 & 14 \\
Pleural effusion & 15 & 606 & 75 & 14 \\
Hematemesis & 16 & 635 & 49 & 8 \\
Dysphagia & 17 & 800 & 93 & 12 \\
Empyema & 12 & 498 & 39 & 8 \\
\hline
\end{tabular}

The diagnostic methods were described based on the analysis of 1059 perforations. The most often diagnosis was the association between clinical and chest $\mathrm{x}$-ray, however in many cases, other diagnosis methods were used complementarily. The esophagogram was used for diagnosis in 606 (57.2\%) patients, computerized tomography in $118(11.1 \%)$, esophagoscopy in $111(10.5 \%)$, and surgery in $20(1.9 \%)$. In 13 cases $(1.2 \%)$ the diagnosis was made only post-mortem, in the autopsy.

Of all 1351 patients, $451(33.4 \%)$ received conservative treatment, $883(65.4 \%)$ received surgical treatment, and $17(1.2 \%)$ received no treatment at all, because they were diagnosed after death or died before receiving any treatment.

Twenty-three studies reported the time from the occurrence of perforation and the diagnosis with a total of 892 patients. Five hundred twelve $(57.4 \%)$ patients were diagnosed before $24 \mathrm{~h}$ while $380(42.6 \%)$ patients were diagnosed after 24 hours.

There was a statistically significant difference between mortality and the time of diagnosis in 14 included studies with a total of 469 patients analyzed. From this total, 263 patients that were diagnosed early $(<24 \mathrm{~h}) 11.8 \%(\mathrm{n}=31)$ died. However, for patients that were diagnosed after $24 \mathrm{~h}$ there were $73(35.4 \%)$ deaths from a total of 206 patients $(\mathrm{p}<0.0001)$.

The mortality rate according to etiology was higher in spontaneous perforation (210 patients, $26.7 \%$ ), with statistically significant difference $(\mathrm{p}<0.001)$ between caustic $(28$ patients, $17.8 \%$ ), traumatic (130 patients, $14.6 \%$ ) and iatrogenic (503 patients, $14.3 \%$ ) perforations.

Regarding mortality, 20 studies (808 patients) reported the location of esophageal perforation in which 176 patients presented in the cervical area and from these, there were $12(6.8 \%)$ deaths. Furthermore, there were 130 (24.3\%) deaths among 535 patients with thoracic perforations, and 19 (19.6\%) among 97 patients with abdominal perforations (Table 2). Mortality on cervical perforation was significantly smaller than thoracic and abdominal $(p<0.0001)$, but there was no significant difference between thoracic and abdominal $(\mathrm{p}=0.31)$. 
TABLE 2 - Mortality rates according to perforation's localization, number of patients, number and percentage of mortality.

\begin{tabular}{cccc}
\hline Localization & n. of patients & $\begin{array}{c}\text { n. of } \\
\text { mortality }\end{array}$ & Mortality (\%) \\
\hline Cervical & 176 & 12 & 6.8 \\
Thoracic & 535 & 130 & 24.3 \\
Abdominal & 97 & 19 & 19.6 \\
\hline
\end{tabular}

From a total of 1351 patients evaluated throughout 31 studies the overall mortality was $18.8 \%(\mathrm{n}=254)$. There were $96(21.2 \%)$ and $144(16.3 \%)$ deaths among 451 and 883 patients that received conservative treatment and surgical treatment, respectively. All the patients who did not receive any treatment died (Table 3). Mortality was significantly lower in those who underwent surgical treatment compared to conservative treatment $(\mathrm{p}=0.025)$.

TABLE 3 - Mortality rates according treatment: surgery, conservative treatment and no treatment.

\begin{tabular}{ccccc}
\hline Study & $\begin{array}{c}\text { Surgical } \\
\text { treatment }\end{array}$ & $\begin{array}{c}\text { Conservative } \\
\text { treatment }\end{array}$ & $\begin{array}{c}\text { No } \\
\text { treatment }\end{array}$ & Total \\
\hline $\begin{array}{c}\text { Patients } \\
\text { n (\%) }\end{array}$ & $883(65.4)$ & $451(33.4)$ & $14(1.2)$ & $1351(100)$ \\
$\begin{array}{c}\text { Overall } \\
\text { mortality } \\
\text { rate n (\%) }\end{array}$ & $144(16.3)$ & $96(21.2)$ & $14(100)$ & $254(18.8)$ \\
\hline
\end{tabular}

\section{Discussion}

Although, esophageal perforation is uncommon it is always a medical emergency, with a very broad clinical presentation and, because of these characteristics the feasibility to perform clinical trials is compromised, including the randomization process that seems challenge to do in such a population. So far, the current evidence about the efficacy of treatment for perforations is based only in case series studies.

The iatrogenic is, indeed, the most prevalent ${ }^{13-15}$ etiology, as it was also noted in approximately half of the total cases in our study however it has the best prognosis while spontaneous etiology has one of the worse prognosis, and it is, unfortunately, the second in prevalence.

The esophageal perforation at the thoracic portion was the most frequent location found throughout the case series included in this study and actually it has the most controversial conduct ${ }^{16}$ with a high rate of morbidity and mortality, especially due to the easy contamination of the mediastinum and the pleural cavity ${ }^{17}$.

The signs and symptoms found in the case series patients were nonspecific and this makes early diagnosis more difficult. However it was noticed that, in most patients, the diagnosis was made by the association between the clinical symptoms and chest radiographic examination. The esophagogram was also used to reach a diagnosis, and it was performed in about $60 \%$ of the patients. Some authors consider it to be the gold standard examination to establish the diagnosis of esophageal lesions ${ }^{18,19}$.

Tomography was found to be not used often as a diagnostic, but this technique was not largely available in the 70s in which 25 studies did not report this approach.

Regarding the time between the perforation and the diagnosis, there was a difference that favored early diagnosis $(<24$ hours). Late diagnosis led to a much higher mortality rate, as shown by Eroglu et al. ${ }^{4}$. However, this issue is become controversial as some authors have questioned whether the mortality does depends on the time elapsed between the lesion and the intervention ${ }^{20-22}$.

The chosen conduct should be started as soon as possible and, for some authors the definitive treatment is the first option. Grillo et al. ${ }^{23}$, Wright et al. ${ }^{24}$ and Port et al. ${ }^{25}$ support performing primary repair regardless of the time between the lesion and the intervention, a conduct that is not approved by Goldstein et al. ${ }^{26}$, Flynn et al. ${ }^{27}$ and Salo et al. ${ }^{28}$, in which they recommend the repair of the perforation only for patients diagnosed before 24 hours.

Some factors could be taken into consideration to help making the decision. One of them would be the etiology, for example, in case the rupture has been spontaneous, there might has high mediastinum contamination by food remains and stomach contents; whereas in iatrogenic perforation, which usually occurs with fasting patients, the rate of wound contamination is lower. Therefore, the former case requires a more aggressive treatment with surgical cleansing and appropriate drainage ${ }^{29}$, which, at the time, could also include repairing the perforation; whereas, in the latter case, the approach could be more conservative.

In cases of foreign object retention, besides surgical cleansing, repair should also be tried when possible. In cases that include any other esophageal pathology in which surgery has already been recommended in the absence of perforation such as locally advanced esophageal cancer, achalasia or non-dilatable strictures, surgery should be performed immediately after the instrumental perforation ${ }^{17}$.

Another factor for deciding on a conduct is the location 
of perforation. Cervical perforations are less aggressive $e^{30,31}$ and can thus be treated conservatively ${ }^{32}$ more often than thoracic perforations, besides that cervical interventions have low morbidity and mortality rates. As proposed by Mantzoukis et al. ${ }^{33}$ treatment using endoclip endoscopy could be an option in case of proximal esophageal perforation.

On the other hand, in intra-abdominal distal esophageal perforations, there is no doubt that repair should be the treatment of choice ${ }^{34}$ due to the difficulty of the organism to lock the lesion in the peritoneal cavity.

Some studies support the endoscopic treatment with selfexpandable stents in acute intra-thoracic perforations, allowing for early oral feeding, reducing the length of hospital stay, besides the fact that they can be removed ${ }^{35,36}$. These authors support the use of the self-expandable metallic stents, regardless of the age, overall condition, time of diagnosis, and etiology of the perforation.

The extension of the lesion and the involvement peri lesional are the most important elements when deciding about the treatment's choices. When the size of the lesion is broad, surgery should be the treatment of choice, whereas cases with smaller lesions could use drainage alone ${ }^{37}$.

The period of time between the perforation and diagnosis should always be kept to a minimum as any delay could lead to necrotizing mediastinitis and, consequently demanding aggressive surgery. Instead, a late diagnosis in patients with a good overall condition could indicate the use of a conservative treatment, because those patients have passed the time test and survived ${ }^{37}$. Nevertheless, Machmouchi et al. ${ }^{38}$ had repaired lesions in two children with over 36 hour of perforation and did get success in both.

\section{Conclusion}

Surgical treatment was more effective and safe than conservative treatment concerning mortality rates, although the possibility of bias due to clinical and methodological heterogeneity among the included studies and the level of evidence that cannot be ruled out.

\section{References}

1. Silvius SE, Nebel O, Rogers G, Sugawa C, Mandelstam P. Endoscopic complications. Results of 1974 American Society of Gastrointestinal Endoscopy Survey. JAMA. 1976;325(9):28-30.

2. Kiernan PD, Rhee J, Collazo L, Byrne WD, Fulcher T, Hettrick V, Vaughan B, Graling P. Thoracic esophageal perforations. South Med. 2003;96(2):158-63.

3. Reeder LB, De Filippi VJ, Ferguson MK. Current results of therapy for esophageal perforation. Am J Surg. 1995;169(6):615-7.

4. Jones WG 2nd, Ginsberg RJ. Esophageal perforation: a continuing challenge. Ann Thorac Surg. 1992;53(3):534-43.

5. Bertelsen S. Traumatic perforation of the oesophagus. Scand J Thorac Cardiovasc Surg. 1971;5(2):103-10.

6. Eschapase H, Gaillard J, Fournial G, Berthoumieu F. Procedure to follow in esophageal perforation (apropos of 27 cases). Ann Chir Thorac Cardiovasc. 1973;12(4):417-21.

7. Nesbitt JC, Sawyers JL. Surgical management of esophageal perforation. Am Surg. 1987;53(4):183-91.

8. Eroglu A, Can Kürkçüogu I, Karaoganogu N, Tekinbaş C, Yimaz O, Başog M. Esophageal perforation: the importance of early diagnosis and primary repair. Dis Esophagus. 2004;17(1):91-4.

9. Zumbro GL, Anstadt MP, Mawulawde K, Bhimji S, Paliotta MA, Pai G. Surgical management of esophageal perforations: role of esophageal conservation in delayed perforation. Am Surg. 2002;68(1):36-40.

10. Kollmar O, Lindermann W, Richter S, Steffen I, Pistorius G, Schilling MK. Boerhaave's syndrome: primary repair vs. esophageal resection- case reports and meta-analysis of literature. J Gastrointest Surg. 2003;7(6):726-34.

11. Orringer MB, Stirling MC. Esophagectomy for esophageal disruption. Ann Thorac Surg. 1990;49(1):35-42.

12. El Dib R, Touma NJ, Kapoor A. Cryoablation versus Radiofrequency Ablation for the Treatment of Renal Cell Carcinoma: a meta-analysis of case series studies. Br J Urol Int. 2012;110(4):510-6.

13. Okten I, Cangir AK, Ozdemir N, Kavukçu S, Akay H, Yavuzer S. Management of esophageal perforation. Surg Today. 2001;31(1):369.

14. Pillay SP, Ward M, Cowen A, Pollard E. Oesophageal ruptures and perforations - a review. Med J Aust. 1989;150(5): 246-52.

15. Altorjay A, Kiss J, Vörös A, Sziranyi E. The role of oesophagectomy in the management of oesophageal perforations. Ann Thorac Surg. 1998;65(5):1433-6.

16. Moghissi K, Pender D. Instrumental perforations of the oesophagus and their management. Thorax. 1988;43(8):642-6.

17. Andrade AC, Andrade APS. Perfuração de esôfago- Análise de 11 casos. Rev Col Bras Cir. 2008;35(5):292-7.

18. Gimenez A, Franquet T, Erasmus JJ, Martinez S, Estrada P. Thoracic complications of esophageal disorders. Radiographics. 2002;22:247-58.

19. Kiss J. Surgical treatment of oesophageal perforation. Br J Surg. 2008;95(7):805-6.

20. Jougon J, Mc Bride T, Delcambre F, Minniti A, Velly JF. Primary esophageal repair for Boerhaave's syndrome whatever the free interval between perforation and treatment. Eur J Cardiothorac Surg. 2004;25(5):475-9.

21. Sung SW, Park JJ, Kim YT, Kim JH. Surgery in thoracic esophageal perforation: primary repair is feasible. Dis Esophagus. 2002;15(3):204-9.

22. Wang N, Razzouk AJ, Safavi A, Gan K, Van Arsdell GS, Burton PM, Fandrich BL, Wood MJ, Hill AC, Vyhmeister EE, Miranda R, Ahn C, Gundry SR. Delayed primary repair of intrathoracic esophageal perforation: is it safe? J Thorac Cardiovasc Surg. 1996;111(1):11421.

23. Grillo HC, Wilkins EW Jr. Esophageal repair following late diagnosis of intrathoracic perforation. Ann Thorac Surg. 1975;20(4):387-99.

24. Wright CD, Mathisen DJ, Wain JC, Moncure AC, Hilgenberg $\mathrm{AD}$, Grillo HC. Reinforced primary repair of thoracic esophageal perforation. Ann Thorac Surg. 1995;60(2):245-8.

25. Port JL, Kent MS, Korst RJ, Bacchetta M, Altorki NK. Thoracic esophageal perforations: a decade of experience. Ann Thorac Surg. 
2003;75(4):1071-4.

26. Goldstein LA, Thompson WR. Esophageal perforations: a 15 year experience. Am J Surg. 1982;143(4):495-503.

27. Flynn AE, Verrier ED, Way LW, Thomas AN, Pellegrini CA. Esophageal Perforation. Arch Surg. 1989;124(10):1211-4.

28. Salo JA, Isolauri JO, Heikkilä LJ, Markkula HT, Heikkinen LO, Kivilaakso EO, Mattila SP. Management of delayed esophageal perforation with mediatinal sepsis. Esophagectomy or primary repair? J Thorac Cardiovasc Surg. 1993;106(6):1088-91.

29. Michel L, Grillo HC, Malt RA. Operative and nonoperative management of esophageal perforations. Ann Surg. 1981;194(1):5763.

30. Borba Junior CO, Nigro AJT, Gomes PO, Francisco Neto A. Enxerto de fáscia lata autógena em ferimentos penetrantes provocados no esôfago cervical de cães. Acta Cir Bras. 1998;13(3):184-93.

31. Souza Filho ZA, Ioshii SO, Greca FH, Biondo-Simões MLP, Rocha SL, Duda JR, Oliveira Filho HR. Small intestine submucosa for repair of cervical esophageal lesions in a dog model. Acta Cir Bras. 2003;18(3):224-31.

32. Triggiani E, Belsey R. Oesophageal trauma: incidence, diagnosis, and management. Thorax. 1977;32(3):241-9.

33. Mantzoukis K, Papadimitriou K, Kouvelis I, Theocharidou A Zebekakis P, Vital V, Nikolaidis P, Germanidis G. Endoscopic closure of an iatrogenic rupture of upper esophagus (Lannier's triangle) with the use of endoclips - case report and review of the literature. Ann Gastroenterol. 2011;24(1):55-8.

34. Altorjay A, Kiss J, Vörös A, Bohák A. Nonoperative management of esophageal perforations. Is it justified? Ann Surg. 1997;225(4):41521.

35. Kiev J, Amendola M, Bouhaidar D, Sandhu BS, Zhao X, Maher J. A management algorithm for esophageal perforation. Am J Surg. 2007;194(1):103-6.

36. Johnsson E, Lundell L, Liedman B. Sealing of esophageal perforation or ruptures with expandable metallic stents: a prospective controlled study on treatment efficacy and limitations. Dis Esophagus. 2005;18(4):262-6.

37. Vogel SB, Rout WR, Martin TD, Abbitt PL. Esophageal perforation in adults: aggressive, conservative treatment lowers morbidity and mortality. Ann Surg. 2005;241(6):1016-21.

38. Machmouchi MA, Bakhsh KA, Al-Harbi MA, Al-Shareef ZH. Pleural flap for delayed presentation of intrathoracic esophageal perforation. Saudi Med J. 2004;25(9):1267-9.

\section{Correspondence:}

Daniele Cristina Cataneo

Disciplina de Cirurgia Torácica, Departamento de Cirurgia e Ortopedia Faculdade de Medicina de Botucatu, UNESP

18618-970 Botucatu - SP Brasil

Tel.: (55 14)3811-6091

Fax: (55 14)3815-7615

dcataneo@,fmb.unesp.br

Received: December 12, 2012

Review: February 14, 2013

Accepted: March 18, 2013

Conflict of interest: none

Financial source: none

${ }^{1}$ Research performed at Botucatu School of Medicine, Sao Paulo State University (UNESP), Botucatu-SP, Brazil. Part of Master degree thesis, Postgraduate Program in General Basis of Surgery. Tutors: José Guilherme Minossi and Daniele Cristina Cataneo. 